\title{
Hydrological performance of Sedum species compared to perennial herbaceous species on a full- scale green roof in Italy
}

\author{
I. Stojkov ${ }^{1,4}$, S.S. Cipolla ${ }^{1 *}$, M. Maglionico ${ }^{2}$, A. Bonoli², A. Conte ${ }^{2}$, L. Ferroni ${ }^{3}$ and M. Speranza ${ }^{3}$ \\ ${ }^{1}$ Interdepartmental Centre for Industrial Research-Building and Construction, University of Bologna, Bologna, \\ Italy; ${ }^{2}$ Department of Civil, Chemical, Environmental, and Materials Engineering, University of Bologna, Bologna, \\ Italy, ${ }^{3}$ Department of Agricultural Sciences, University of Bologna, Bologna, Italy, ${ }^{4}$ Kleinfelder Northeast, \\ Cambridge, MA, USA.
}

\begin{abstract}
Although the ability of green roofs as stormwater source control technologies has been the topic of many recent studies, most conclude that a better understanding of full-scale hydrological performance and of the impact of different plant cover types is still needed. Based on these considerations, this research presents the results of 15 months of monitoring activity in Bologna (Italy) studying the hydrological performance of two adjacent full-scale extensive green roof plots with a different plant cover composition. One of the plots (SR) was planted with Sedum species (CAM) and the other (NR) with native herbaceous perennial species (C3). Continuous rainfall, runoff and weather data were collected and used to compare the effect of changing plant cover type on the green roof retention rate. Over the 15 months of this study, NR presented a $59 \%$ retention rate (111 valid events) whereas SR had a $52 \%$ retention rate (91 valid events). For 24 common events, with retention lower than $100 \%$, the average difference between the NR and SR plot retention was $10 \%$, confirming the higher water storage capacity, and therefore the higher retention rate, of the NR plot.
\end{abstract}

Keywords: Stormwater; runoff; retention; monitoring; CAM; C3; extensive green roofs

\section{INTRODUCTION}

Source Control technologies, such as green roofs (GR) and permeable pavements, are often used to reduce the volume of stormwater runoff coming from impervious areas, restoring the pre-urbanized hydrological conditions (Cipolla et al., 2016a) and consequently reducing the negative impact of CSOs (Casadio et al., 2013) and urban heat. There is extensive literature on the hydrological behavior of GRs, see Carson et al. (2013); and Stovin et al. (2012) for an overview. To date, the rainfall retention, which represents the amount of water trapped during an event by all the layers, is the most common parameter used to evaluate the hydrological performance of GRs. Recent syntheses on monitoring activities on GRs suggest that retention varies between $11.0 \%$ and $76.4 \%$ (Cipolla et al., 2016b). This variability is attributable to a multitude of factors, such as the study location, the length of the monitoring period, the substrate depth and the vegetation type. By far the most commonly used green roof vegetation is a mix of Sedum species, primarily because they are able to grow rapidly and can survive extended water deficits. Under moisture stress, Sedum species are able to adopt the CAM (Crassulacean Acid Metabolism) photosynthesis mode with reduced daytime transpiration to conserve moisture (Cushman and Borland, 2002). Recently, however, researchers at Hong Kong (Jim, 2014) and in U.K (Blanusa et al., 2013), have demonstrated, through field experiments, a better cooling service achieved by herbaceous species, due to differences in daily evapotranspiration loss rates. This is achieved because they maintain the C3 metabolism, which is more water consuming than the CAM one, even in water shortages.

*E-mail: sara.cipolla@unibo.it 
Agreeing with these findings, some hydraulic engineers are investigating the differences in runoff reduction derived by the use of different vegetation mixes (Nagase and Dunnett, 2012).

Based on the above, the main objectives of this study can be summarize as following: a) measuring and comparing the hydrological performance of two different types of plant cover on two real scale extensive green roof plots located on the same building, and therefore exposed to the same weather conditions and external factors in Bologna (Italy); b) analyzing the monitoring data in agreement with previous studies (Carson et al., 2013) with the goal of developing and following common standard.

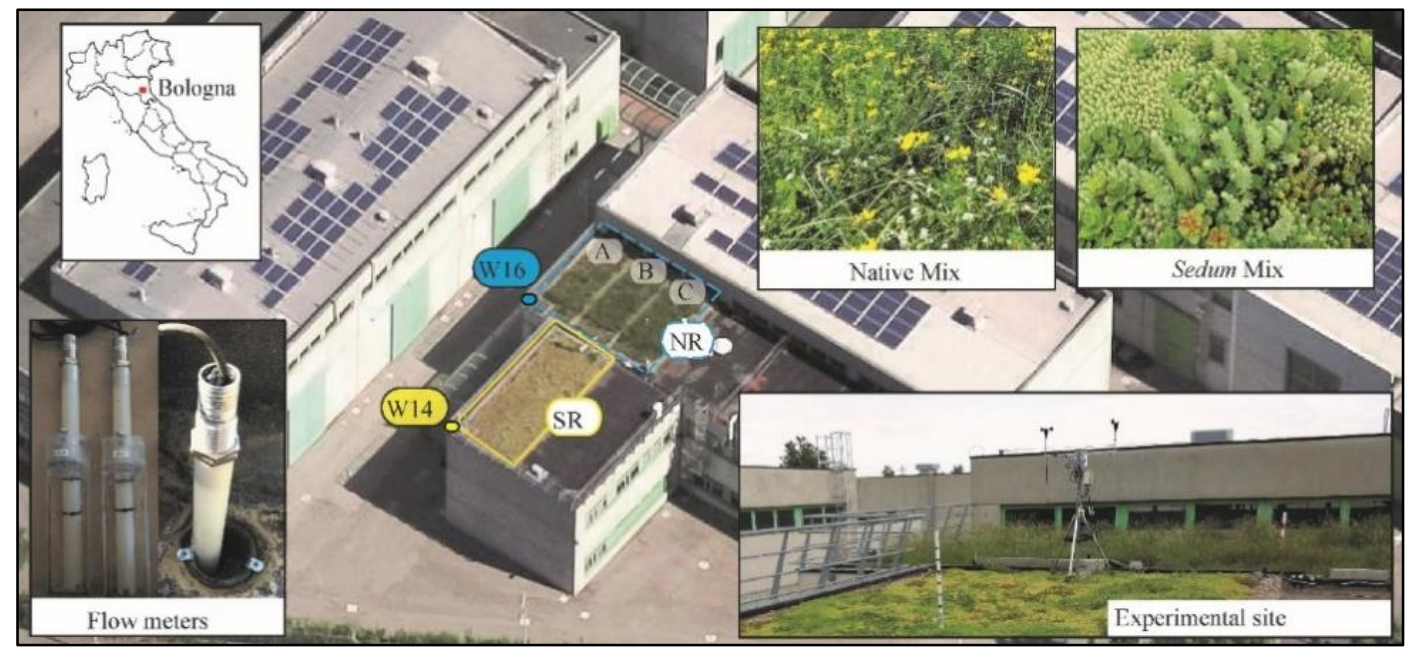

Figure 1. Green roof experimental site at University of Bologna (Italy): aerial view showing the extensive Sedum plot (SR), the extensive Native plot (NR), the position of the in-pipe flow meters (W14 and W16 respectively for SR and NR), and the Sedum and Native mix of species planted on the plots.

\section{MATERIALS AND METHODS (EXPERIMENTAL PROCEDURES)}

The two experimental GR plots in this study are both located on a flat roof on the LAGIRN laboratory $\left(44.513058^{\circ} \mathrm{N}, 11.318787^{\circ} \mathrm{E}\right)$ of the University of Bologna. The experimental site (Bonoli et al., 2013) covers about $130 \mathrm{~m}^{2}$ of the existing flat roof, and hosts two full-scale extensive green plots, as shown in Fig. 1. The geometry and the properties of each layer, included the substrate characteristics, are described in Cipolla et al. (2016). The SR plot consists of about $58 \mathrm{~m}^{2}$ of green area, with a constant substrate depth of $10 \mathrm{~cm}$, planted with a Sedum mix of: Sedum hispanicum, Sedum album, Sedum reflexum, Sedum sexangulare (Fig. 1). The Native Roof (NR) plot is a $72 \mathrm{~m}^{2}$ green area divided by gravel paths into three subplots each one of about $24 \mathrm{~m}^{2}$ with an average depth of $10 \mathrm{~cm}$. The plant cover is made of three perennial herbaceous species from local spontaneous populations, adapted to semi-arid areas. More specifically, the species are: Bromus erectus (Poaceae), Dorycnium pentaphyllum (Leguminosae) and Lotus corniculatus (Leguminosae) (Fig. 1). During the experimental activities, only NR required constant sprinkler irrigation in the summer of 2014 $(\sim 2.5 \mathrm{~mm}$ for day). The field instrumentation for runoff observations consisted of in-pipe flow meters (see Fig. 1) located in each internal downspout and connected to a HOBO weather station. A full description of the experimental setup and instrumentation can be found in Cipolla et al. (2016) and Carson et al. (2013). Retention for each event was calculated as the percentage of rainfall which did not run off from the roof (Stovin et al., 2012).

Rainfall and runoff data were continuously collected from October 2013 to December 2014 for each plot. The study resulted in 91 and 111 valid storm events, from the originally collected 122 and 134, respectively for the SR and the NR plots (Tab. 1). To be able to assign the runoff quantity to the event that generated it, individual rainfall events were defined as a precipitation recorded after a minimum $6 \mathrm{~h}$ dry period where no precipitation or runoff was found for that plot (Cipolla et al., 2016, Carson et al., 2013). This is why the total number of 
rainfall events for each plot can result in a slightly different number, confirming their retention behavior is different.

\begin{tabular}{|c|c|c|c|c|c|c|}
\hline \multirow{2}{*}{$\begin{array}{l}\text { Name } \\
\text { \# Total Events }\end{array}$} & \multicolumn{3}{|c|}{ SEDUM (SR) } & \multicolumn{3}{|c|}{ NATIVE (NR) } \\
\hline & 122 & & Retention & 134 & & Retention \\
\hline \# Valid Events & 91 & $74.6 \% \mathrm{o}^{\mathrm{t}}$ & $52.0 \%$ & 111 & $82.8 \%^{\mathrm{t}}$ & $59.0 \%$ \\
\hline \# Events $(0-10 \mathrm{~mm})$ & 76 & $83.5 \% \mathrm{v}$ & $81.0 \%$ & 86 & $77.5 \% \mathrm{v}$ & $85.3 \%$ \\
\hline \# Events (10-20 mm) & 9 & $9.9 \% \mathrm{v}$ & $57.1 \%$ & 17 & $15.3 \%^{v}$ & $71.6 \%$ \\
\hline \# Events $(20-30 \mathrm{~mm})$ & 2 & $2.2 \% \mathrm{v}$ & $11.2 \%$ & 2 & $1.8 \% \mathrm{v}$ & $34.8 \%$ \\
\hline \# Events (30-40 mm) & 3 & $3.3 \% \mathrm{v}$ & $29.8 \%$ & 2 & $1.8 \% \mathrm{v}$ & $55.5 \%$ \\
\hline \# Events (40-50 mm) & 1 & $1.1 \%^{\mathrm{v}}$ & $24.5 \%$ & 3 & $2.7 \%{ }^{v}$ & $30.9 \%$ \\
\hline \# Events $(50+\mathrm{mm})$ & 0 & - & - & 1 & $0.9 \% \mathrm{v}$ & $4.7 \%$ \\
\hline \# Winter Events (Dec-Feb) & 28 & $30.8 \%{ }^{v}$ & $38.4 \%$ & 35 & $31.5 \%{ }^{v}$ & $70.5 \%$ \\
\hline \# Spring Events (Mar-May) & 17 & $18.7 \% \mathrm{v}$ & $47.8 \%$ & 19 & $17.1 \% \mathrm{v}$ & $65.6 \%$ \\
\hline \# Summer Events (Jun-Aug) & 3 & $3.3 \% \mathrm{v}$ & $26.5 \%$ & 20 & $18.0 \% \mathrm{v}$ & $40.3 \%$ \\
\hline \# Fall Events (Sep-Nov) & 43 & $47.3 \% \mathrm{v}$ & $66.7 \%$ & 37 & $33.3 \% \mathrm{v}$ & $60.5 \%$ \\
\hline
\end{tabular}

\section{RESULTS AND DISCUSSION}

The retention values for the valid events resulted in a retention of $59 \%$ and $52 \%$ and a peak attenuation of $80 \%$ and $78 \%$ respectively for NR and SR, thus indicating that both GRs are effective in retaining stormwater runoff. These findings are consistent with previous studies (Cipolla et al., 2016b, Carson et al., 2013). Despite the GR system being the same for both roofs, Table 1 shows that SR and NR differed in terms of average retention in time and per rainfall depth. During most events and consistently with prior studies (Vanwoert et al., 2005), the plot covered by perennial herbaceous species (NR) showed a slightly higher retention.

The rainfall-runoff relationship for the common events only was studied to better investigate these differences. An event was considered "common" when its start date and time were the same for both plots and the total rainfall depth within the event was identical. This investigation resulted in 66 common events of which only 24 had a retention lower than $100 \%$ (Fig. 2). Figure 2 shows that for 19 of the 24 common events, NR had a higher retention than the SR plot with an average retention of $74 \%$ and $64 \%$ respectively. These findings confirm the higher water storage capacity, and therefore the higher retention rate of NR.

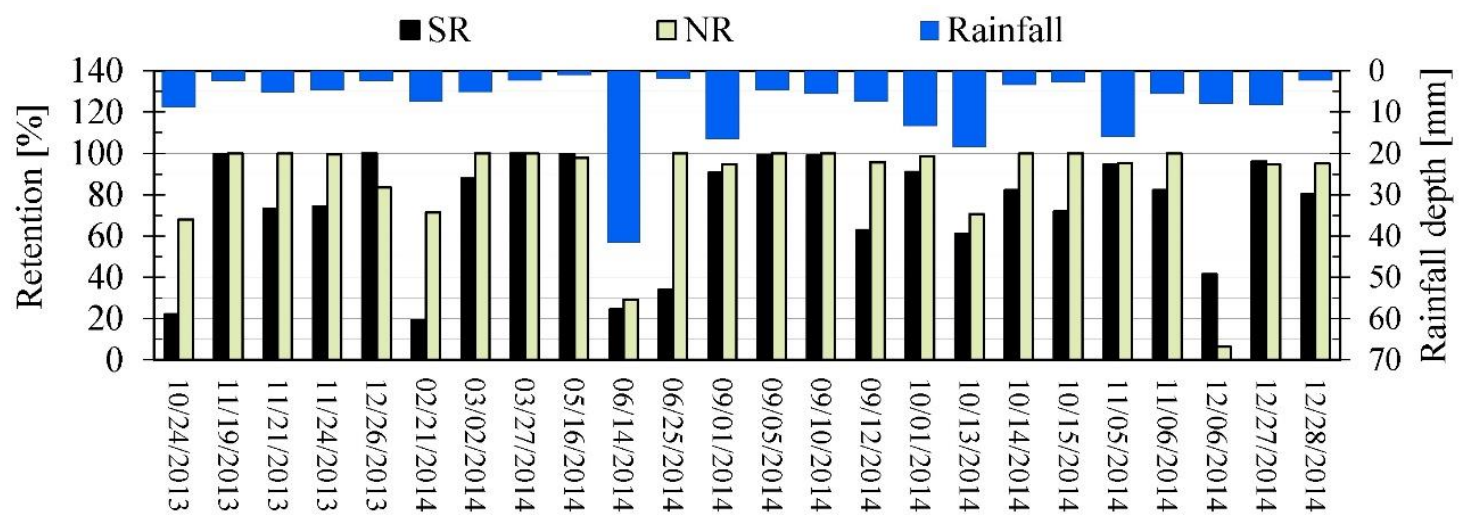

Figure 2. Retention performance observed during 24 common events with runoff $>0$, for the SR and NR plots 


\section{CONCLUSIONS}

This study has demonstrated the ability of two full-scale extensive green roof plots to retain rainfall from individual precipitation events. Moreover, as different species with different metabolism were planted on the two plots (CAM facultative Sedum species and C3 herbaceous perennial native species) their hydrological performance was compared. The two plots were able to retain water with an average retention of $59 \%$ and $52 \%$ respectively for NR and SR over 15 months. Retention was found to correlate strongly with rainfall depth, decreasing for larger rainfall events due to the finite retention capacity of the roof.

Furthermore, the study shows that the retention is influenced by the differences in plant cover. During the 24 common events with non-zero retention for both plots, retention was $10 \%$ higher for the native plant mix (C3 herbaceous perennial species) compared to the Sedum species (CAM facultative species). This result is likely attributable to the simultaneous interaction of two factors which are: a) the plant biomass developed by the native species during the growing season being larger than the Sedum mix's and b) the higher evapotranspiration losses of the native mix due to its water-consuming C3 metabolism than evapotranspiration losses of the Sedum species. However, future research is needed to quantify the daily evapotranspiration losses in time of both the plots.

\section{Licterature cited}

Blanusa, T., Vaz Monteiro, M.M., Fantozzi, F., Vysini, E., Li, Y. and Cameron, R.W.F. (2013). Alternatives to Sedum on green roofs: Can broad leaf perennial plants offer better 'cooling service'? Build. Environ. 59, 99-106 http://dx.doi.org/10.1016/j.buildenv.2012.08.011

Bonoli, A., Conte, A., Maglionico, M. and Stojkov, I. (2013). Green roofs for sustainable water management. Environ. Eng. Manag. J. 12, 153-156

Carson, T.B., Marasco, D.E., Culligan, P.J. and McGillis, W.R. (2013). Hydrological performance of extensive green roofs in New York City: observations and multi-year modeling of three full-scale systems. Environ. Res. Lett. 8, 113. doi:10.1088/1748-9326/8/2/024036

Casadio, A., Cipolla, S.S., Maglionico, M. and Martinini, P. (2013). Numerical modeling of the sewer system of Rimini (Italy) and strategies for the CSOs reduction on the Adriatic Sea. Environ. Eng. Manag. J. 12, 121-124

Cipolla, S.S., Maglionico, M. and Stojkov, I. (2016a). Experimental Infiltration Tests on Existing Permeable Pavement Surfaces. Clean - Soil, Air, Water 44(1), 89-95. doi:10.1002/clen.201400550

Cipolla, S.S., Maglionico, M. and Stojkov, I. (2016b). A long-term hydrological modelling of an extensive green roof by means of SWMM. Ecol. Eng. 95, 876-887 http://dx.doi.org/10.1016/j.ecoleng.2016.07.009

Cushman, J.C. and Borland, A.M. (2002). Induction of Crassulacean acid metabolism by water limitation. Plant, Cell Environ. 25, 295-310 http://dx.doi.org/10.1046/j.0016-8025.2001.00760.x

Jim, C.Y. (2014). Heat-sink effect and indoor warming imposed by tropical extensive green roof. Ecol. Eng. 62, 112 http://dx.doi.org/10.1016/j.ecoleng.2013.10.022

Nagase, A. and Dunnett, N. (2012). Amount of water runoff from different vegetation types on extensive green roofs: Effects of plant species, diversity and plant structure. Landsc. Urban Plan. 104, 356-363. http://dx.doi.org/10.1016/j.landurbplan.2011.11.001

Nektarios, P.A., Ntoulas, N., Nydrioti, E., Kokkinou, I., Bali, E.M. and Amountzias, I. (2014). Drought stress response of Sedum sediforme grown in extensive green roof systems with different substrate types and depths. Sci. Hortic. (Amsterdam). 181, 52-61 http://dx.doi.org/doi:10.1016/j.scienta.2014.10.047

Sayed, O.H., Earnshaw, M.J. and Cooper, M. (1994). Growth, water relations, and CAM induction in Sedum album in response to water stress. Biol. Plant. 36, 383-388. http://dx.doi.org/10.1007/BF02920936

Stovin, V., Vesuviano, G. and Kasmin, H. (2012). The hydrological performance of a green roof test bed under UK climatic conditions. J. Hydrol. 414-415, 148-161 http://dx.doi.org/doi:10.1016/j.jhydrol.2011.10.022

Vanwoert, N.D., Rowe, D.B., Andresen, J.A., Rugh, C.L., Fernandez, R.T. and Xiao, L. (2005). Green Roof Stormwater Retention: Effects of Roof Surface, Slope, and Media Depth 1044, 1036-1044. http://dx.doi.org/10.2134/jeq2004.0364 